\title{
Discordant Observation of Brain Injury by MRI and Malignant Electroencephalography Patterns in Comatose Survivors of Cardiac Arrest following Therapeutic Hypothermia
}

\author{
(D).M. Mettenburg, (D). Agarwal, (D). Baldwin, and (D).C. Rittenberger
} on

\begin{abstract}
BACKGROUND AND PURPOSE: Malignant electroencephalography patterns are considered predictive of poor outcome in comatose survivors of cardiac arrest. We hypothesized that malignant patterns on electroencephalography are associated with evidence of more severe brain injury on MR imaging.
\end{abstract}

MATERIALS AND METHODS: Retrospective review of clinical, imaging, and electroencephalography data of 33 adult comatose survivors of cardiac arrest following therapeutic hypothermia was performed. Outcomes measured included discharge destination and survival. Imaging studies were visually scored for severity of brain injury. Mean whole-brain apparent diffusion coefficient and percentage of severely injured brain (ADC $<700 \times 10^{-6} \mathrm{~mm}^{2} / \mathrm{s}$ ) were calculated. Continuous electroencephalographic interpretation was characterized as malignant or nonmalignant. Nonparametric tests were performed to assess the relationship of patient outcome, MR imaging, and electroencephalography patterns.

RESULTS: Subjects with anatomic evidence of diffuse brain injury were less likely to have malignant electroencephalography patterns. Subjects with malignant electroencephalography patterns, invariably associated with bad outcomes, were observed to have whole-brain apparent diffusion coefficient measures similar to those in subjects with nonmalignant electroencephalography patterns and good outcome and different from those in subjects with nonmalignant electroencephalography patterns and bad outcomes. Regional hippocampal or basal ganglia injury was associated with a bad outcome regardless of electroencephalography findings.

CONCLUSIONS: We found discordant evidence of brain injury by MR imaging and electroencephalography, refuting our initial hypothesis. Malignant electroencephalography patterns were generally more frequent in subjects with less severe brain injury by MR imaging. These findings suggest a complementary role of MR imaging and electroencephalography and support the aggressive treatment of malignant electroencephalography patterns in this population.

ABBREVIATIONS: $\mathrm{EEG}=$ electroencephalography; $\mathrm{GPD}=$ generalized periodic discharges; $\mathrm{wbADC}=$ whole-brain apparent diffusion coefficient

$\mathbf{P}$ rognostication of survival and functional outcome in comatose survivors of cardiac arrest is challenging. A multimodal approach to prognostication, including continuous electroencephalography (EEG) patterns, clinical assessment of initial illness severity, MR imaging, spontaneous and evoked potentials,

Received September 2, 2015; accepted after revision April 16, 2016.

From the Departments of Radiology (J.M.M., V.A.), Neurology (M.B.), and Emergency Medicine (J.C.R.), University of Pittsburgh, Pittsburgh, Pennsylvania.

This work was supported by the National Institutes of Health through grant No. UL1-TR-000005.

Please address correspondence to Joseph M. Mettenburg, MD, PhD, UPMC, Presbyterian Shadyside, Department of Radiology, 200 Lothrop St, PUH 2nd Floor, Suite 200 East Wing, Pittsburgh, PA 15213; e-mail: mettenburgjm@upmc.edu

-- Indicates open access to non-subscribers at www.ajnr.org

E Indicates article with supplemental on-line table.

http://dx.doi.org/10.3174/ajnr.A4839 and serum biomarkers, has been recommended. ${ }^{1-5}$ The role of MR imaging is not standardized despite relatively good sensitivity and specificity documented in studies performed before routine therapeutic hypothermia. ${ }^{6,7}$ However, brain imaging and malignant EEG patterns following therapeutic hypothermia have not been comprehensively described, to our knowledge. We hypothesize that malignant EEG patterns are associated with greater extent of brain injury evident on MR imaging, which would explain the typically poor outcomes within this subset of patients. Understanding the relationship between these modalities may establish an evidenced-based role for MR imaging in prognostication following cardiac arrest.

\section{MATERIALS AND METHODS}

This study was approved by the University of Pittsburgh institutional review board. Informed consent was not required by the 
institutional review board for this retrospective study because these data are included as part of an ongoing quality-assurance initiative.

\section{Study Population}

All subjects were comatose adults $24-80$ years of age admitted at a single tertiary care center following resuscitation from an in- or out-of-hospital cardiac arrest between April 14, 2010, and October 29, 2011. All subjects underwent a standardized care plan including therapeutic hypothermia for 24 hours with a target temperature of $33^{\circ} \mathrm{C} .{ }^{8}$ This plan includes aggressive coronary revascularization for patients with coronary ischemia, given its association with improved outcomes. ${ }^{9}$ MRI and EEG were ordered at the discretion of the attending physician, and only individuals with both continuous EEG and MR imaging were included. Continuous EEG monitoring was performed for at least 48 hours and was initiated within a median time of 9 hours. ${ }^{10}$ EEG recordings were continued beyond 48 hours in those with malignant EEG patterns.

\section{Demographics, Details of Cardiac Arrest, and Outcome}

A review of the clinical record was performed to obtain the following: age, sex, initial cardiac rhythm, survival, disposition at the time of hospital discharge, EEG pattern, time from arrest to MR imaging, Glasgow Coma Scale at the time of MR imaging, and length of stay in the hospital. Demographics were compared between groupings on the basis of clinical outcome and EEG patterns by using nonparametric Kruskal-Wallis and Fisher exact tests. Outcome was based on survival and disposition at the time of hospital discharge. ${ }^{11}$ A good outcome was defined as survival with discharge home or acute inpatient rehabilitation. Other dispositions, including death, persistent vegetative state, and nursing home admission, were considered bad outcomes (Online Table 1).

\section{EEG Interpretation}

EEG interpretations were characterized as previously defined. ${ }^{2,10}$ EEG data and reports were analyzed and classified by using 3 EEG categories, depending on the presence of malignant EEG patterns, pure suppression burst, or nonmalignant EEG patterns. We characterized the following EEG patterns as malignant: seizures, generalized periodic discharges (GPD), status epilepticus, and myoclonic status epilepticus. The EEG classification definitions are based on the American Clinical Neurophysiological Society Standardized Critical Care EEG Terminology to define equivocal patterns seen in patients with encephalopathy and for management of status epilepticus. ${ }^{12-15}$ All EEGs were independently reviewed by a board-certified neurophysiologist with specialization in EEG and with expertise in postarrest EEG interpretation (M.B.). ${ }^{16}$ The electrophysiologist reviewing these studies may have provided the initial clinical interpretation; however, determination of malignant patterns was performed at a time remote from the initial clinical presentation and was blinded to the patient's outcome and initial presentation.

\section{MR Imaging and Analysis}

All included subjects underwent clinical MR imaging of the brain during their hospitalization, with typical imaging parameters (Optima 450w 1.5T; GE Healthcare, Milwaukee, Wisconsin; DWI acquisition parameters: $\mathrm{b}$-value $=1000,3$ directions, $\mathrm{TR}=8000$ $\mathrm{ms}, \mathrm{TE}=$ minimum, $\mathrm{FOV}=26,5 / 1$ section/gap with a $128 \times 128$ matrix size, asset-enabled for artifacts reduction; T2-FLAIR acquisition parameters: $\mathrm{TE}=120-160 \mathrm{~ms}, \mathrm{TR}=8000-10,000 \mathrm{~ms}$, $\mathrm{TI} \sim 2250 \mathrm{~ms}, \mathrm{FOV}=22,5 / 1$ section/gap with a $256 \times 192$ matrix size, NEX $=1$ ). The extent of supratentorial gyral restricted diffusion was visually scored ${ }^{17-19}$ as subtotal or diffuse (examples in Fig 1). The subtotal manifestations included a normal appearance or restricted diffusion evident in focal areas, more posterior involvement, or basal ganglia only. Involvement of the hippocampus and basal ganglia (unilateral or bilateral) was recorded independently. Diffuse gyral edema as evidenced by expansile gyral T2 signal abnormality and sulcal effacement, independent of DWI findings, was recorded as present or absent. All images were visually inspected by 3 Certificate of Added Qualification-certified neuroradiologists (J.M.M., V.A., H. Kale) who were blinded to clinical data and whole-brain ADC measures; disagreement was mediated by $2 / 3$ consensus.

\section{Whole-Brain ADC Measurements}

ADC maps were retrospectively segmented by using a mask derived from the FSL Brain Extraction Tool (http://fsl.fmrib.ox.ac. $\mathrm{uk} / \mathrm{fs} \mathrm{l} / \mathrm{fs}$ wiki/BET) by using the B0 image of the DWI and thresholding to include only voxels with $\mathrm{ADC}<1000 \times 10^{-6} \mathrm{~mm}^{2} / \mathrm{s}$, to exclude CSF-containing spaces. All extracted and thresholded ADC maps were visually inspected for artifacts or errors of processing. Whole-brain mean ADC (wbADC) values were generated by using fslstats (http://fsl.fmrib.ox.ac.uk/fsl/fslwiki/Fslutils). In addition, the percentage of whole-brain voxels with $\mathrm{ADC}$ values $<700 \times 10^{-6}$ $\mathrm{mm}^{2} / \mathrm{s}$ was determined by dividing the number of voxels in the brain below $700 \times 10^{-6} \mathrm{~mm}^{2} / \mathrm{s}$ by the total number of voxels contained in the extracted and thresholded ADC maps. ${ }^{6}$

\section{Statistical Analysis}

Subjects were divided according to patterns of brain injury observed by MR imaging: diffuse cortical restricted diffusion compared with those with no, focal, or posterior patterns of restricted diffusion; the presence or absence of hippocampal injury on DWI/ADC; and the presence or absence of gyral edema. Fisher exact test analyses of the association of EEG patterns with imaging findings were performed.

Values of wbADC were compared among the following subjects: 1) those with a malignant EEG pattern, 2) those without a malignant EEG pattern who had a good outcome, and 3) subjects without a malignant EEG pattern who had a bad outcome. There were no subjects with a malignant EEG pattern and a good outcome. Median values and interquartile ratings of wbADC were determined; nonparametric Kruskal-Wallis testing was performed to evaluate the distribution of observed values across groups, including age, time from arrest to MR imaging, and whole brain ADC measures. The Pearson correlation coefficient was calculated to determine the relationship of mean whole-brain ADC and time from arrest to MR imaging. 

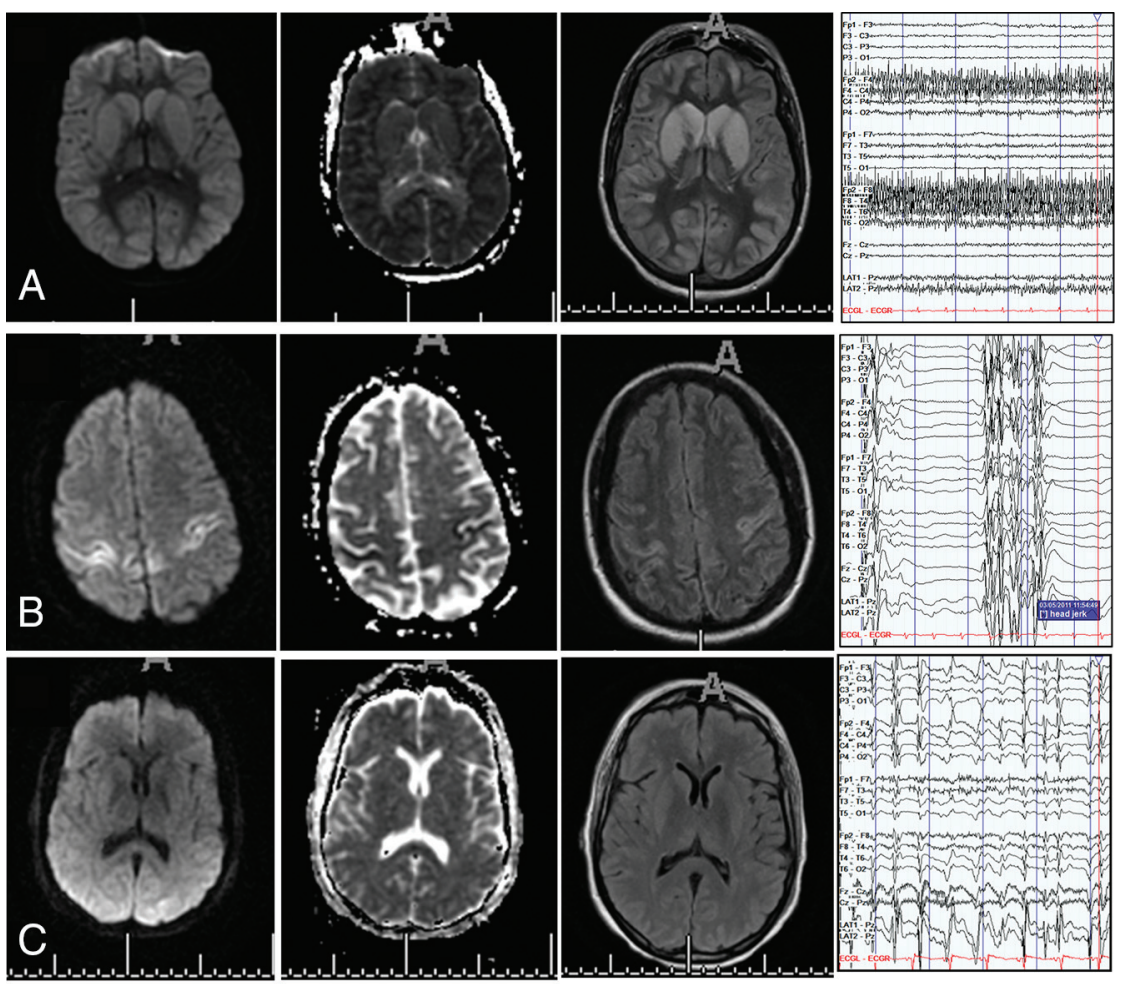

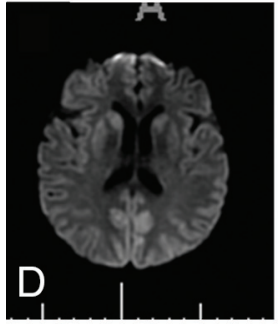

DWI

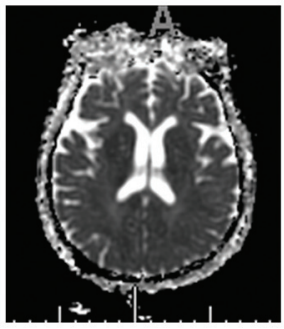

$\mathrm{ADC}$

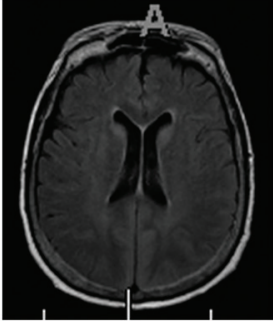

T2-FLAIR

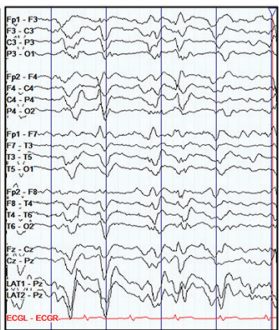

EEG

FIG 1. Selected examples of patterns of DWI, ADC, and T2-FLAIR abnormalities in subjects without $(A)$ and with $(B-D)$ malignant EEG patterns (longitudinal bipolar montage [low-frequency filter, $1 \mathrm{~Hz}$; high-frequency filter, $70 \mathrm{~Hz} ; 60-\mathrm{Hz}$ notch on; sensitivity, $7 \mathrm{uV} / \mathrm{mm}])$. All of these subjects had bad outcomes (death, coma, or persistent vegetative state at discharge). A, Diffuse gyral edema and restricted diffusion, wbADC $=666 \times 10^{-6} \mathrm{~mm}^{2} / \mathrm{s}$. EEG (nonmalignant) pattern of diffuse background slowing. $B$, Focal diffusion abnormality involves the sensorimotor cortices, wbADC $=$ $835 \times 10^{-6} \mathrm{~mm}^{2} / \mathrm{s}$. EEG demonstrates a (malignant) suppression burst pattern. Bursts are associated with clinical jerks. $C$, Essentially normal MR imaging appearance of the brain, wbADC $=782 \times$ $10^{-6} \mathrm{~mm}^{2} / \mathrm{s}$. EEG demonstrates a (malignant) pattern of generalized periodic discharges. $D$, Posterior (parietal) diffusion abnormality with little gyral edema, wbADC $=824 \times 10^{-6} \mathrm{~mm}^{2} / \mathrm{s}$. EEG (malignant) pattern of GPDs.

\section{RESULTS}

No subjects were excluded after visual inspection of masked and thresholded ADC maps for artifacts or obvious errors. Basic demographics comparing the groupings on the basis of a malignant pattern of EEG and outcome are presented in Table 1. Length of stay did not differ among the 3 groups. The Glasgow Coma Scale score on the day of MR imaging did not differ between those with malignant or nonmaliganant EEGs who experienced poor neurologic outcomes.

\section{EEG Pattern and Outcome}

Among the 9 patients with malignant EEG patterns, all (100\%) had bad outcomes. Among the 24 patients with nonmalignant EEG patterns, 12 had bad outcomes ( $P=.012$, Fisher exact test). Of note, all except 1 of the patients with a malignant pattern demonstrated GPDs alone (see examples, Fig $1 C,-D)$. The remaining patients' continuous EEGs demonstrated epileptiform discharges and myoclonic status epilepticus in addition to GPDs (Fig 1B).

\section{Patterns of Brain Injury Associated with Groupings Based on EEG Pattern and Outcome}

Table 2 demonstrates associations of patterns of brain injury evident on MR imaging with groupings based on EEG patterns and outcome. There was no significant difference in the presence or absence of diffuse gyral edema among the groups; however, there were significant differences based on the pattern of restricted diffusion and evidence of either basal ganglia or hippocampal involvement.

\section{Whole-Brain ADC Measures}

There were no subjects with a good outcome and malignant EEG patterns. The distribution of the number of days from arrest to MR imaging was not significantly different among groups on the basis of outcome and EEG findings. There was no significant correlation of mean wbADC values with the time from arrest to MR imaging (Pearson $r=$ 0.22).

Nonparametric testing of the distribution of mean wbADC and percentage of brain voxels with $\mathrm{ADC}$ values $<700 \times$ $10^{-6} \mathrm{~mm}^{2} / \mathrm{s}$ between groups based on outcome and EEG patterns resulted in $P$ values of .151 and .082, respectively (Fig 2). There was a large variance evident in the population with nonmalignant EEG and bad outcome.

\section{DISCUSSION}

This study demonstrates a discordant pattern of brain injury demonstrated on MR imaging, continuous EEG patterns, and outcome in comatose survivors of cardiac arrest. While this and other studies have demonstrated that a malignant EEG pattern is associated with poor outcome, it was assumed that the underlying brain injury evident by MR imaging was also severe and extensive. ${ }^{10,20,21}$ Our study suggests otherwise. Although associated with poor outcomes, patients with malignant EEG patterns were observed to have less extensive evidence of structural brain injury by MR imaging, despite similar Glasgow Coma Scale scores at the time of MR imaging.

Under the current clinical protocol, continuous EEG is obtained during the first 48 hours, including a period of therapeutic 


\begin{tabular}{|c|c|c|c|c|c|}
\hline & $\begin{array}{l}\text { Malignant } \\
\text { EEG }(n=0)\end{array}$ & $\begin{array}{l}\text { Malignant } \\
\text { EEG }(n=9)\end{array}$ & $\begin{array}{c}\text { Nonmalignant } \\
\text { EEG }(n=12)\end{array}$ & $\begin{array}{c}\text { Nonmalignant } \\
\text { EEG }(n=12)\end{array}$ & $\begin{array}{c}P \\
\text { Value }\end{array}$ \\
\hline Outcome & Good & Bad & Good & Bad & \\
\hline Age (median) (IQR) & NA & $50(42.5-59.5)$ & $53.5(43.5-63.0)$ & $58.5(43-66.0)$ & .252 \\
\hline Female (No.) (\%) & NA & $8(89)$ & $4(33)$ & $6(50)$ & .051 \\
\hline Arrest to MRI (median days) (IQR) & NA & $3(2.5-5.0)$ & $5(4.3-10.3)$ & $4(3-4)$ & .065 \\
\hline Length of stay (median days) (IQR) & NA & $9(5-18)$ & $23(13-27)$ & $13.5(6-24.5)$ & .077 \\
\hline GCS at time of MRI (median score) (IQR) & & $4(3-6)$ & $10^{\mathrm{b}}(8.5-14)$ & $6(3.5-8)$ & .0014 \\
\hline \multicolumn{6}{|l|}{ Rhythm of arrest (No.) } \\
\hline Asystole & NA & 2 & 3 & 3 & .71 \\
\hline PEA & NA & 2 & 1 & 4 & \\
\hline VF/VT & NA & 4 & 6 & 5 & \\
\hline Unknown & NA & 1 & 2 & 0 & \\
\hline \multicolumn{6}{|l|}{ Location of arrest (No.) } \\
\hline In hospital & NA & 2 & 1 & 3 & .53 \\
\hline Out of hospital & NA & 7 & 11 & 9 & \\
\hline
\end{tabular}

Note:-IQR indicates interquartile range; PEA, pulseless electrical activity; VF/VT, ventricular fibrillation/ventricular tachycardia; NA, not applicable; GCS, Glasgow Coma Scale. ${ }^{a}$ There were no individuals with malignant EEG and good outcome in this cohort. There were no significant differences by groupings using Kruskal-Wallis and Fisher exact tests for nonparametric analysis of continuous and categoric variables, respectively; sex and days from arrest to MRI were nearly significant with $P=.051$ and .065 , respectively. ${ }^{b} p<.01$ for comparison with the bad outcome groups; nonsignificant difference between the bad outcome groups.

Table 2: Patterns of brain injury evident on MRI with groupings based on EEG and outcome with the Fisher exact test

\begin{tabular}{|c|c|c|c|c|c|}
\hline & $\begin{array}{l}\text { Malignant } \\
\operatorname{EEG}(n=0)\end{array}$ & $\begin{array}{l}\text { Malignant } \\
\operatorname{EEG}(n=9)\end{array}$ & $\begin{array}{l}\text { Nonmalignant } \\
\text { EEG }(n=12)\end{array}$ & $\begin{array}{l}\text { Nonmalignant } \\
\text { EEG }(n=12)\end{array}$ & $\begin{array}{c}P \\
\text { Value }\end{array}$ \\
\hline Outcome & Good & Bad & Good & Bad & \\
\hline $\begin{array}{l}\text { No. with diffuse pattern of } \\
\text { restricted diffusion (\%) }\end{array}$ & NA & $0(0)$ & $1(8.3)$ & $5(41.7)$ & .05 \\
\hline $\begin{array}{l}\text { No. with diffuse pattern of } \\
\text { gyral edema }(\%)\end{array}$ & NA & $3(33)$ & $1(17)$ & $6(50)$ & .25 \\
\hline $\begin{array}{l}\text { No. with restricted diffusion } \\
\text { in basal ganglia (any) (\%) }\end{array}$ & NA & $4(44)$ & $1(17)$ & $10(83)$ & .005 \\
\hline $\begin{array}{l}\text { No. with restricted diffusion } \\
\text { in the hippocampi (\%) }\end{array}$ & NA & $1(11)$ & $0(0)$ & $5(50)$ & .009 \\
\hline
\end{tabular}

Note:-NA indicates not applicable.

hypothermia. Our findings suggest that a malignant EEG pattern may not reflect diffuse cortical injury. Patients with malignant EEG patterns do not reliably demonstrate MR imaging evidence of anatomic injury. Therefore, mechanisms other than cortical injury may influence the development of malignant EEG patterns. Aggressive pre-emptive treatment to prevent the development or persistence of malignant EEG patterns may also prevent additional brain injury and improve patient outcomes. ${ }^{22}$

Dysregulation of electrophysiology networks, leading to periodic-type malignant patterns, may contribute to a comatose state in the absence of anatomic injury evident by MR imaging. The underlying mechanism generating these patterns is not well-understood but is supported by the observation that most patients with epilepsy do not have lesions. Furthermore, injured subcortical and brain stem generators of electrophysiologic activity may contribute to malignant patterns when disproportionately affected, compared with cortical structures. Cobb and Hill ${ }^{23}$ first proposed a theory of "cortical isolation," suggesting that severing connectivity between the cortex and subcortical structures resulted in periodic patterns. These cortical-subcortical networks have been characterized in preclinical models of seizures, ${ }^{24-26}$ and others have reported periodic EEG patterns generated by injury to cortical-subcortical white matter in the absence of cortical injury. ${ }^{27,28}$ Gloor et al ${ }^{29}$ reviewed postmortem examinations of patients with periodic lateralized epileptiform discharges and saw gray matter lesions only, and metabolic or electrophysiologic etiologies were also implicated in GPDs. ${ }^{30,31}$ These findings suggest a role for the coordination of cortical and subcortical/brain stem structures in maintaining healthy network electrophysiology.

This discordant findings of malignant pattern/poor outcome and relatively benign MR imaging appearance may explain, in part, why the prognostic value of MR imaging and ADC mapping has been limited by a poor predictive performance, given a large number of false-negatives (ie, individuals with relatively normal-appearing findings on MRI yet with poor outcome). ${ }^{6,7,32}$ Although some of these patients die from causes unrelated to ongoing CNS pathology, diffuse cortical brain injury may be incompatible with the generation of malignant EEG patterns, whereas focal insults and/or relative preservation of regions of uninjured brain may predispose to the development of malignant EEG patterns, in particular GPDs. Unfortunately, it is unclear to what extent therapeutic hypothermia may alter brain MR imaging findings after cardiac arrest. Given the results of the targeted temperature management trial, ${ }^{33}$ future work may address this question.

Although nonparametric testing of whole-brain measures of ADC did not reach a significance of $P<.5$ (Fig 2), there was a clear disproportionate trend evident in the population with malignant EEG patterns and bad outcome that was discordant from the population with bad outcome and no evidence of malignant EEG patterns, best demonstrated by evaluation of the extent of ADC values $<700 \times 10^{-6} \mathrm{~mm}^{2} / \mathrm{s}$. Future neuroprognostication tools will need to characterize patients on the basis of clinical, electrophysiologic, and neuroanatomic testing to determine optimal therapy and predict outcomes.

Once thought to be a rare pattern, GPD has increasingly been observed in patients in the intensive care unit due to more aggres- 

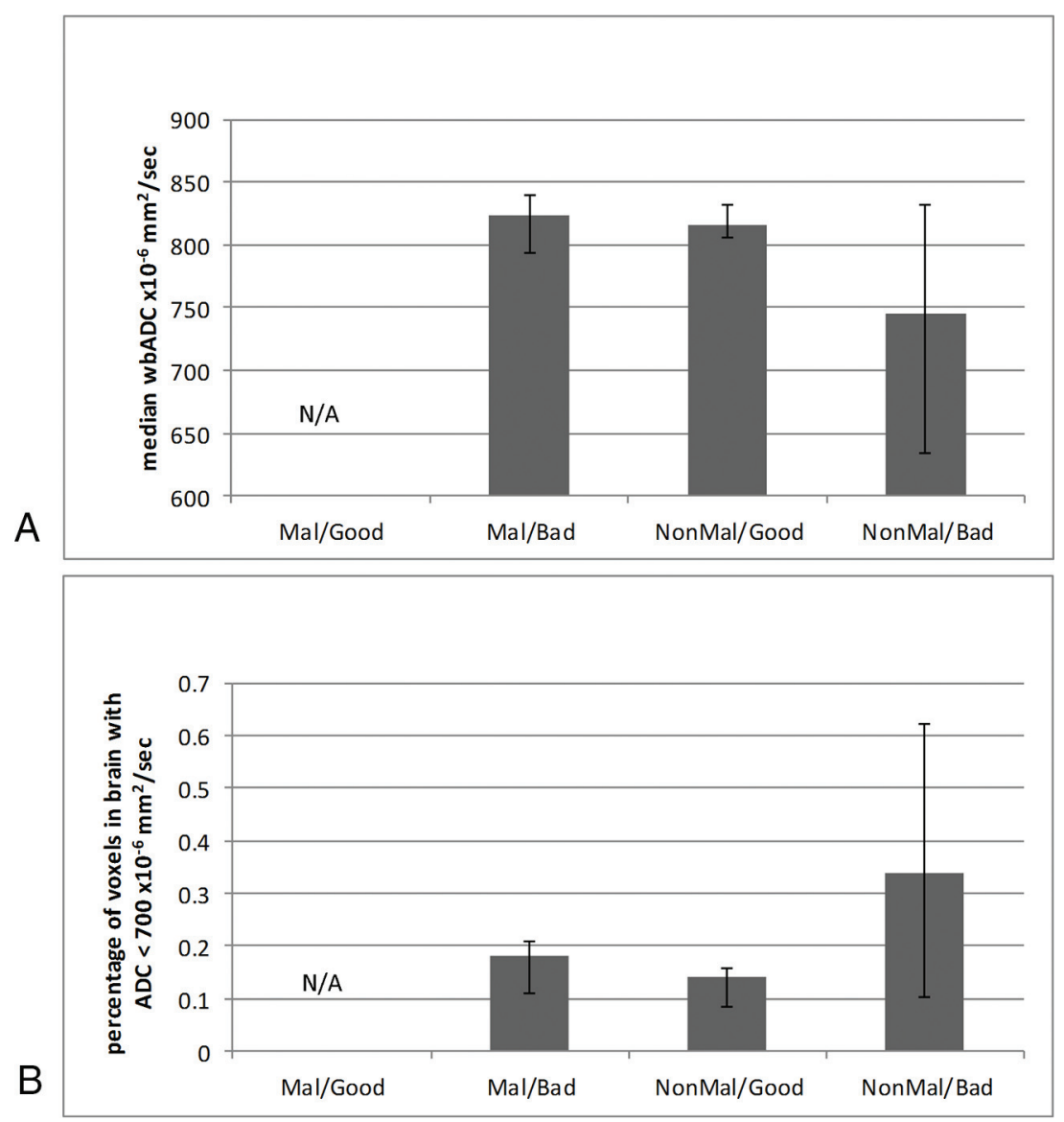

FIG 2. Whole-brain median ADC values compared among groups based on a pattern of EEG and outcome (median \pm interquartile ratio). A, Whole-brain ADC $\times 10^{-6} \mathrm{~mm}^{2} / \mathrm{s}$. B, Percentage of brain voxels with $A D C<700 \times 10^{-6} \mathrm{~mm}^{2} / \mathrm{s}$. There were no subjects with a malignant pattern and good outcome. Mal indicates malignant EEG; NonMal, nonmalignant EEG.

sive continuous EEG monitoring. However, there is still no consensus on the pathophysiologic generators of GPD, seen in diverse settings: infectious processes (Creutzfeldt-Jakob disease, subacute sclerosing panencephalitis), drug overdoses (lithium, ketamine, phencyclidine, baclofen), anoxia (cardiac arrest), status epilepticus, and metabolic states (hepatic and uremic encephalopathy). ${ }^{30,31}$ GPD is associated with poor outcome following cardiac arrest, except when observed in isolation. ${ }^{34}$ In our study, GPD was common and associated with less extensive evidence of brain injury by MR imaging. A prior study reported that $21.4 \%$ of patients with GPD patterns had normal imaging findings. ${ }^{30}$ Hippocampal DWI signal abnormality was more commonly associated with bad outcome ${ }^{35}$ but was also significantly more frequent in those without malignant EEG patterns.

Injury to the basal ganglia and hippocampus as evidenced by restricted diffusion had a greater likelihood of a bad outcome, though these findings were not uniformly associated with the presence of a malignant EEG pattern. Regional variations in brain injury have been shown in cardiac arrest preceded by respiratory arrest, ${ }^{36}$ and hippocampal injury is associated with poor outcome. ${ }^{35}$ Initial arrest may result in a watershed-type injury to both hippocampi. ${ }^{37}$ Impaired bilateral limbic network function may preclude meaningful recovery despite intact cortical networks and motor function. Such findings may reflect a different mechanism of injury or may be related to extracranial multiorgan dysfunction. Within this retrospective cohort, there was aggressive treatment of epileptiform activity with antiepileptic drugs, which may alter the nature of ictal discharges. However, 8 of the 9 subjects with a malignant pattern demonstrated this pattern on day 1 , before initiation of antiepileptiform drugs. No EEG was obtained after day 3 , indicating that all malignant patterns were successfully suppressed by this time. However, some individuals may have delayed development of malignant EEG patterns not captured in this retrospective study but perhaps contributing to subsequent imaging findings. Most important, these findings suggest that anatomic lesions may not be good predictors of pathologic electrophysiology.

One hypothesis is that abnormal interactions between the "deranged cortex" and deeper "triggering" structures in the setting of increased local cortical irritability likely contribute to periodic patterns. ${ }^{29,38}$ These abnormal interactions may or may not be associated with lesions evident on MR imaging. Herpes encephalitis and posterior reversible encephalopathy syndrome are processes in which malignant EEG patterns can be seen with normal MR imaging findings and are potentially reversible. Quantitative analysis of continuous EEGs may help clarify underlying neuropathophysiology in cardiac arrest and subsequent resuscitation. Complex patterns involving subcortical networks have been described by Moretti et al ${ }^{39}$ in memory impairment and dementias. This type of quantitative analysis may provide a fundamentally different observation than the current qualitative assessment presented here.

The primary limitations of this study include a small sample size and the retrospective nature of the study. There is a selection bias against the most severely ill patients, who were perhaps never imaged. Furthermore, the MR imaging and EEG interpretations were available to the treating physicians and likely influenced decisions to withdraw support, potentially resulting in a self-fulfilling prophecy. However, length of stay did not differ among the groups, suggesting that there was no systematic bias based on early withdrawal of care, and the mean length of stay for all groups substantially exceeded published clinical guidelines. ${ }^{40,41}$ Prospective studies including MR imaging and EEG are indicated to mitigate this potential bias. Whole-brain measures of ADC do not evaluate regional brain injury. Future studies should evaluate long-term outcomes at least 3 months postdischarge; the recovery phase is dynamic and may require up to 1 year. ${ }^{42}$

Early malignant EEG patterns identified within a subset of comatose patients after cardiac arrest treated with therapeutic hy- 
pothermia are not associated with more extensive evidence of brain injury on MR imaging. The prevalent recording of global periodic discharges in this cohort suggests a possible metabolic or reversible etiology for the periodic pattern, or intact cortex salvageable if further injury is prevented. Regional injury to hippocampal or basal ganglia structures may predict poor outcome irrespective of EEG findings, potentially reflecting different mechanisms of arrest. These findings demonstrate the importance of considering both EEG and MR imaging data for comatose survivors of cardiac arrest and support aggressive treatment of malignant patterns.

\section{CONCLUSIONS}

Patients with malignant EEG patterns were observed to have less MR imaging evidence of brain injury yet remained associated with poor outcome in this retrospective study. GPD, a pattern that was previously considered rare, was the most common malignant pattern observed. This electrophysiologic pattern may be more common in the posttherapeutic hypothermia era and may represent a reversible injury. These findings demonstrate the importance of integrating both EEG and MR imaging data when evaluating comatose survivors of cardiac arrest. Aggressive pre-emptive treatment to prevent the development, persistence, or progression of malignant EEG patterns may prevent additional brain injury and improve patient outcomes.

\section{ACKNOWLEDGMENTS}

We are appreciative of the excellent clinical care and data collection by the Post Cardiac Arrest Service at the University of Pittsburgh Medical Center. Special thanks are extended to Dr Hrishikesh Kale for his contribution to the imaging analysis.

Disclosures: Jon M. Rittenberger-UNRELATED: Grants/Grants Pending: National Institutes of Health funding, American Heart Association Grant-in-Aid, and Laerdal Foundation for Acute Medicine, Comments: grant support for other projects germane to anoxic brain injury.

\section{REFERENCES}

1. Bouwes A, Binnekade JM, Verbaan BW, et al. Predictive value of neurological examination for early cortical responses to somatosensory evoked potentials in patients with postanoxic coma. $\mathrm{JNeu}$ rol 2012;259;537-41 CrossRef Medline

2. Coppler PJ, Elmer J, Calderon L, et al; Post Cardiac Arrest Service. Validation of the Pittsburgh Cardiac Arrest Category illness severity score. Resuscitation 2015;89:86-92 CrossRef Medline

3. Levy DE, Caronna JJ, Singer $\mathrm{BH}$, et al. Predicting outcome from hypoxic-ischemic coma. JAMA 1985;253:1420-26 Medline

4. Taccone F, Cronberg $\mathrm{T}$, Friberg $\mathrm{H}$, et al. How to assess prognosis after cardiac arrest and therapeutic hypothermia. Crit Care 2014;18: 202 CrossRef Medline

5. Young GB. Clinical practice: neurologic prognosis after cardiac arrest. $N$ Engl J Med 2009;361:605-11 CrossRef Medline

6. Wijman CA, Mlynash M, Caulfield AF, et al. Prognostic value of brain diffusion-weighted imaging after cardiac arrest. Ann Neurol 2009;65:394-402 CrossRef Medline

7. Choi SP, Park KN, Park HK, et al. Diffusion-weighted magnetic resonance imaging for predicting the clinical outcome of comatose survivors after cardiac arrest: a cohort study. Crit Care 2010;14:R17 CrossRef Medline

8. Rittenberger JC, Guyette FX, Tisherman SA, et al. Outcomes of a hospital-wide plan to improve care of comatose survivors of cardiac arrest. Resuscitation 2008;79:198-204 CrossRef Medline
9. Reynolds JC, Callaway CW, El Khoudary SR, et al. Coronary angiography predicts improved outcome following cardiac arrest: propensity-adjusted analysis. J Intensive Care Med 2009;24:179-86 CrossRef Medline

10. Rittenberger JC, Popescu A, Brenner RP, et al. Frequency and timing of nonconvulsive status epilepticus in comatose post-cardiac arrest subjects treated with hypothermia. Neurocrit Care 2012;16:114-22 CrossRef Medline

11. Rittenberger JC, Tisherman SA, Holm MB, et al. An early, novel illness severity score to predict outcome after cardiac arrest. Resuscitation 2011;82:1399-404 CrossRef Medline

12. Chong DJ, Hirsch LJ. Which EEG patterns warrant treatment in the critically ill? Reviewing the evidence for treatment of periodic epileptiform discharges and related patterns. J Clin Neurophysiol 2005; 22:79-91 CrossRef Medline

13. Hirsch LJ, LaRoche SM, Gaspard N, et al. American Clinical Neurophysiology Society's Standardized Critical Care EEG Terminology: 2012 version. J Clin Neurophysiol 2013;30:1-27 CrossRef Medline

14. Westhall E, Rosén I, Rossetti AO, et al. Interrater variability of EEG interpretation in comatose cardiac arrest patients. Clin Neurophysiol 2015;126:2397-404 CrossRef Medline

15. Brophy GM, Bell R, Claassen J, et al; Neurocritical Care Society Status Epilepticus Guideline Writing Committee. Guidelines for the evaluation and management of status epilepticus. Neurocrit Care 2012;17: 3-23 CrossRef Medline

16. Amorim E, Rittenberger JC, Baldwin ME, et al; Post Cardiac Arrest Service. Malignant EEG patterns in cardiac arrest patients treated with targeted temperature management who survive to hospital discharge. Resuscitation 2015;90:127-32 CrossRef Medline

17. Arbelaez A, Castillo M, Mukherji SK. Diffusion-weighted MR imaging of global cerebral anoxia. AJNR Am J Neuroradiol 1999;20:9991007 Medline

18. Wijdicks EF, Campeau NG, Miller GM. MR imaging in comatose survivors of cardiac resuscitation. AJNR Am J Neuroradiol 2001;22: 1561-65 Medline

19. Singhal AB, Topcuoglu MA, Koroshetz WJ. Diffusion MRI in three types of anoxic encephalopathy. J Neurol Sci 2002;196:37-40 Medline

20. Knight WA, Hart KW, Adeoye OM, et al. The incidence of seizures in patients undergoing therapeutic hypothermia after resuscitation from cardiac arrest. Epilepsy Res 2013;106:396-402 CrossRef Medline

21. Sadaka F, Doerr D, Hindia J, et al. Continuous electroencephalogram in comatose postcardiac arrest syndrome patients treated with therapeutic hypothermia: outcome prediction study. J Intensive Care Med 2015;30:292-96 CrossRef Medline

22. Brain Resuscitation Clinical Trial I Study Group. Randomized clinical study of thiopental loading in comatose survivors of cardiac arrest. N Engl J Med 1986;314:397-403 CrossRef Medline

23. Cobb W, Hill D. Electroencephalogram in subacute progressive encephalitis. Brain 1950;73:392-404 CrossRef Medline

24. Avoli M, Kostopoulos G. Participation of corticothalamic cells in penicillin-induced generalized spike and wave discharges. Brain Res 1982;247:159-63 CrossRef Medline

25. Gioanni Y, Gioanni H, Mitrovic N. Seizures can be triggered by stimulating non-cortical structures in the quaking mutant mouse. Epilepsy Res 1991;9:19-31 Medline

26. Gloor P. Generalized epilepsy with bilateral synchronous spike and wave discharge: new findings concerning its physiological mechanisms. Electroencephalogr Clin Neurophysiol Suppl 1978;(34):245-49 Medline

27. Vercueil L, Hirsch E. Seizures and the basal ganglia: a review of the clinical data. Epileptic Disord 2002;4(suppl 3):S47-54 Medline

28. Badawy RA, Lai A, Vogrin SJ, et al. Subcortical epilepsy? Neurology 2013;80:1901-07 Medline

29. Gloor P, Kalabay O, Giard N. The electroencephalogram in diffuse encephalopathies: electroencephalographic correlates of grey and white matter lesions. Brain 1968;91:779-802 CrossRef 
30. Yemisci M, Gurer G, Saygi S, et al. Generalised periodic epileptiform discharges: clinical features, neuroradiological evaluation and prognosis in 37 adult patients. Seizure 2003;12:465-72 CrossRef Medline

31. Janati A, Chesser MZ, Husain MM. Periodic lateralized epileptiform discharges (PLEDs): a possible role for metabolic factors in pathogenesis. Clin Electroencephalogr 1986;17:36-43 Medline

32. Greer D, Scripko P, Bartscher J, et al. Clinical MRI interpretation for outcome prediction in cardiac arrest. Neurocrit Care 2012;17: 240-44 CrossRef Medline

33. Nielsen N, Wetterslev J, Cronberg T, et al; TTM Trial Investigators. Targeted temperature management at $33^{\circ} \mathrm{C}$ versus $36^{\circ} \mathrm{C}$ after cardiac arrest. $N$ Engl J Med 2013;369:2197-206 CrossRef Medline

34. Foreman B, Claassen J, Abou Khaled K, et al. Generalized periodic discharges in the critically ill: a case-control study of 200 patients. Neurology 2012;79:1951-60 CrossRef Medline

35. Greer DM, Scripko PD, Wu O, et al. Hippocampal magnetic resonance imaging abnormalities in cardiac arrest are associated with poor outcome. J Stroke Cerebrovasc Dis 2013;22:899-905 CrossRef Medline

36. Drabek T, Foley LM, Janata A, et al. Global and regional differences in cerebral blood flow after asphyxial versus ventricular fibrillation cardiac arrest in rats using ASL-MRI. Resuscitation 2014;85:964-71 CrossRef Medline
37. Walha K, Ricolfi F, Béjot Y, et al. Hippocampus: a "forgotten" border zone of brain ischemia. J Neuroimaging 2013;23:98-101 CrossRef Medline

38. Brenner RP, Schaul N. Periodic EEG patterns: classification, clinical correlation, and pathophysiology. J Clin Neurophysiol 1990;7: 249-67 CrossRef Medline

39. Moretti DV, Paternicò D, Binetti G, et al. Analysis of grey matter in thalamus and basal ganglia based on EEG $\alpha 3 / \alpha 2$ frequency ratio reveals specific changes in subjects with mild cognitive impairment. ASN Neuro 2012;4:e00103 CrossRef Medline

40. Callaway CW, Donnino MW, Fink EL, et al. Part 8: Post-Cardiac Arrest Care-2015 American Heart Association Guidelines Update for Cardiopulmonary Resuscitation and Emergency Cardiovascular Care. Circulation 2015;132:S465-82 CrossRef Medline

41. Peberdy MA, Callaway CW, Neumar RW, et al; American Heart Association. Part 9: Post-Cardiac Arrest Care-2010 American Heart Association Guidelines for Cardiopulmonary Resuscitation and Emergency Cardiovascular Care. Circulation 2010;122:S768-86 CrossRef Medline

42. Raina KD, Rittenberger JC, Holm MB, et al. Functional outcomes: one year after a cardiac arrest. Biomed Res Int 2015;2015:283608 CrossRef Medline 